\title{
Propagation of Partial Discharge and Noise Pulses in Turbine Generators
}

\author{
Henriksen, Mogens; Stone, G. C.; Kurtz, M.
}

Published in:

IEEE Transactions on Energy Conversion

Link to article, DOI:

10.1109/TEC.1986.4765750

Publication date:

1986

Document Version

Publisher's PDF, also known as Version of record

Link back to DTU Orbit

Citation (APA):

Henriksen, M., Stone, G. C., \& Kurtz, M. (1986). Propagation of Partial Discharge and Noise Pulses in Turbine Generators. IEEE Transactions on Energy Conversion, EC-1(3), 161-166.

https://doi.org/10.1109/TEC.1986.4765750

\section{General rights}

Copyright and moral rights for the publications made accessible in the public portal are retained by the authors and/or other copyright owners and it is a condition of accessing publications that users recognise and abide by the legal requirements associated with these rights.

- Users may download and print one copy of any publication from the public portal for the purpose of private study or research.

- You may not further distribute the material or use it for any profit-making activity or commercial gain

- You may freely distribute the URL identifying the publication in the public portal

If you believe that this document breaches copyright please contact us providing details, and we will remove access to the work immediately and investigate your claim. 
PROPAGATION OF PARTIAL DISCHARGE AND NOISE PULSES IN TURBINE GENERATORS

\author{
M. Henriksen \\ Technical University of Denmark \\ DK-2800 Lyngby \\ Denmark
}

\author{
G.C. Stone, M. Kurtz \\ Ontario Hydro \\ 800 Kipling Avenue \\ Toronto, Canada
}

Abstract - Changes with time in the partial discharge (PD) activity originating in a generator stator's insulation system provide information about the electrical integrity of the stator winding. It is desirable to measure PD during normal service to minimize costs. To do this successfully, the influence of electrical interference must be reduced. Tests are reported which characterize the nature of discharge and noise pulses when using capacitive couplers mounted on each of the phase leads and an RF current transformer mounted on the neutral lead for signal detection. Significant differences between PD and electrical noise have been observed.

\section{INTRODUCTION}

Failure of the stator winding insulation system in large turbo-generators is relatively rare. However, when such failures occur, winding repair or replacement may take from several months to a year. In addition to the repair costs, the replacement energy costs associated with such a failure may be in excess of $\$ 250,000$ a day for nuclear units. The forced outage rate and major winding maintenance can be reduced by monitoring the condition of the stator insulation and performing minor maintenance at an early stage when required. There are several methods available which aid in determining the condition of the insulation: visual inspection; condition monitoring [1]; RF monitoring[2,3]; and partial discharge testing.

Partial discharge testing on rotating machines has been useful in detecting incipient mechanical problems and other insulation deterioration mechanisms, including slot discharge, grading paint deterioration and discharges in internal voids $[2,4]$. Using a partial discharge test which requires no interruption to normal service, Ontario Hydro has significantly reduced the forced outage rate and major maintenance costs in its hydraulic generators [4]. The hydraulic generator PD test measures short risetime PD pulses with pairs of capacitive couplers which are connected in a bridge-like fashion in each phase to eliminate external electrical interference (from arcing brushes, static exciters, relatively harmless discharges in switchgear, communication signals, other electrical machinery, etc).

Attempts to apply similar PD tests to large turbogenerators have been frustrated for several reasons. The coupling system required for hydraulic generators to insure elimination of external noise requires a circuit

85 WM 254-8

A paper reccommended and approved by the IEEE Rotating Machinery Committee of the IEEE Power Engineering Society for presentation at the IEEE/PES 1985 Winter Meeting, New York, New York, February $3-8,1985$. Manuscript submitted August 29, 1984; made available for printing December 12, 1984 . ring bus length in excess of 2 metres[5]. Such long circuit ring buses are not common in turbo generators. Furthermore, the need to penetrate hydrogen seals and the lack of space, complicate the retrofitting of the required coupler pairs. Thus if a successful in-service partial discharge test is to be developed for use on turbo-generators, alternative means of reducing electrical interference, and thus reducing the probability of "false alarms", need to be found.

This paper describes the results of tests to characterize the pulses from partial discharges and from electrical interference on several turbo-generators. The tests were done on standstill machines to discover how simulated $P D$ and noise pulses propagate through the winding, and how noise might be differentiated from PD.

\section{EXPERIMENTAL PROCEDURE}

\section{Methods of Detecting Partial Discharges}

Two principal methods for the on-line electrical detection of PD pulses have been developed for turbo-alternators. One method uses a radio-frequency current transformer (RF CT) mounted on the lead connecting the generator neutral to the neutral grounding transformer $[2,3]$. The other technique employs two high voltage capacitors per phase, mounted on the isolated phase bus (IPB)[5]. These two capacitors can be connected as "directional" couplers, to eliminate electrical noise from the power system, while retaining sensitivity to signals from the generator (PD and "internal" electrical noise).

For the tests described below on standstill machines, both high-frequency CTs and single-capacitive couplers mounted at the generator phase-end terminals were used. The CT was wound on a Ferroxcube $3 \mathrm{C} 6$ split ferrite core and had a ten-turn secondary. The frequency response of the 50-ohm terminated CT was flat from $100 \mathrm{kHz}$ to $30 \mathrm{MHz}$. A low-voltage 68-pF capacitor was also connected to each phase output, usually on the isolated phase bus. The frequency response of the 50ohm terminated capacitive couplers was flat from $30 \mathrm{MHz}$ to in excess of $100 \mathrm{MHz}$. Similar low capacitance, high voltage couplers have been successfully used to detect PD in over 160 hydraulic generators [4].

The response of the capacitive couplers and the CT to simulated PD and electrical noise was recorded on a Tektronix 7104, 1000-MHz oscilloscope and/or a 1.5-G $\mathrm{Gz}$, HP8568A computer-controlled spectrum analyzer.

\section{Simulation of PD and Noise Pulses}

Partial discharges in a winding occur in gas gaps anywhere between the copper conductor and the stator iron, between the stress control paint and the grounded semiconductive coating, or between isolated patches of the coating. PD can also occur in the endwinding region, especially between bars in different phases. In each case a voltage or current pulse will propagate through the winding by a complicated path. 
For the tests, PD pulses were simulated by applying a voltage pulse between the stator iron and a $25-\mathrm{mm} x$ $80-\mathrm{mm}$ adhesive-backed copper foil injection electrode, which was temporarily applied to the surface of a stator bar in a convenient location in the endwinding area. Great effort was required to keep the test leads short. A high-frequency ground plane was established as near as possible to the injection electrode by placing a $30 \times 30-\mathrm{cm}$ copper foil on the stator iron or stator frame. This approach obviated the need for an ohmic electrical connection to the stator iron by removing lamination varnish, etc. By placing a PD-injection electrode on several bars in a winding parallel, the propagation of pulses through the winding was studied.

Electrical noise pulses can enter the stator winding (and thus be confused with PD) from three sources:

1. from the power system, via the generator output leads. This type of external noise, which is adequately attenuated by directional couplers on the isolated phase bus[4,5], was not simulated in these tests:

2. from the high frequency noise on the dc field supply, via capacitive or inductive coupling from the rotor. The high-frequency noise is created by thyristor operation, high shaft potentials, arcing brushes, and coupling from the generator station service;

3. from differential ground rise between parts of the stator frame coupling into the stator winding. Substantial high-frequency voltage pulses have been measured between two points of the same ground plane. The origin of such signals is not clear, but likely sources are arc welders, harmless sparking of floating metal objects near high-current buses, radio transmitters, etc.

The simulation of the above noise pulses was intended to resemble the method of their creation. Noise coupled from the rotor was simulated by injecting voltage pulses onto the rotor shaft or slip rings, with respect to the stator frame. Similarly, ground rise type noise was simulated by injecting a voltage pulse between two points on the stator frame. The distance between the points varied from about 1 metre to 6 metres.

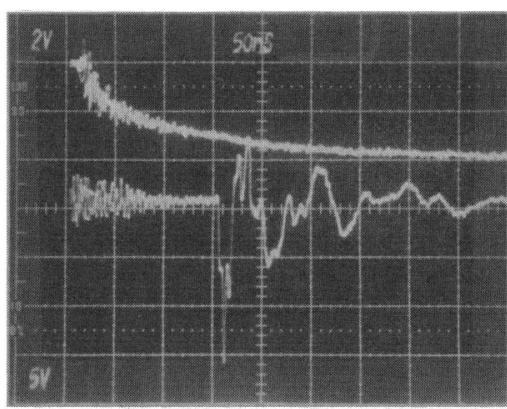

Figure 1: Voltage pulse applied by the spark generator to the injection electrode (top trace). The bottom trace shows the voltage induced on the copper conductor in a coil. A 1000:1 high voltage probe was used to measure the upper trace voltage.

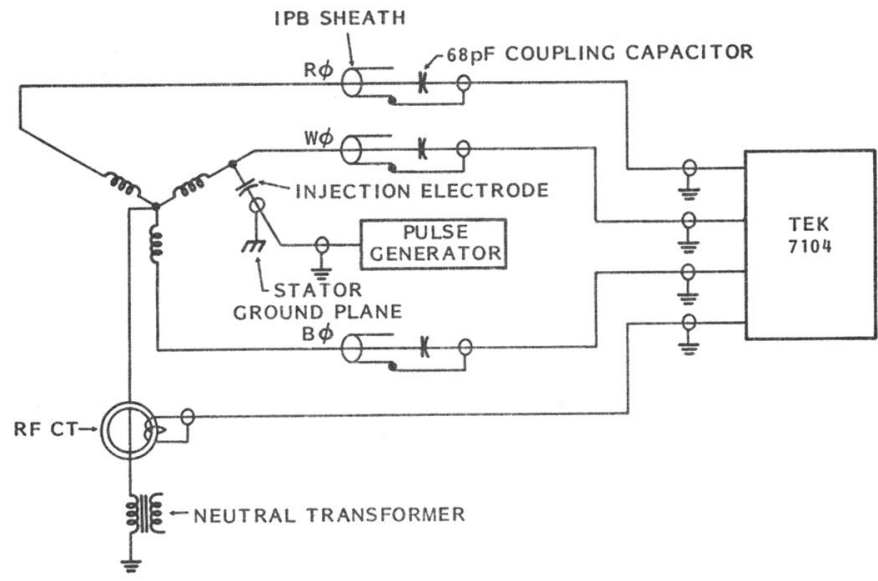

Figure 2: Electrical arrangement for measuring response to simulated $P D$ and noise. Each input to the oscilloscope is terminated in $50 \mathrm{ohms}$. The oscilloscope is directly triggered by the pulse generator.

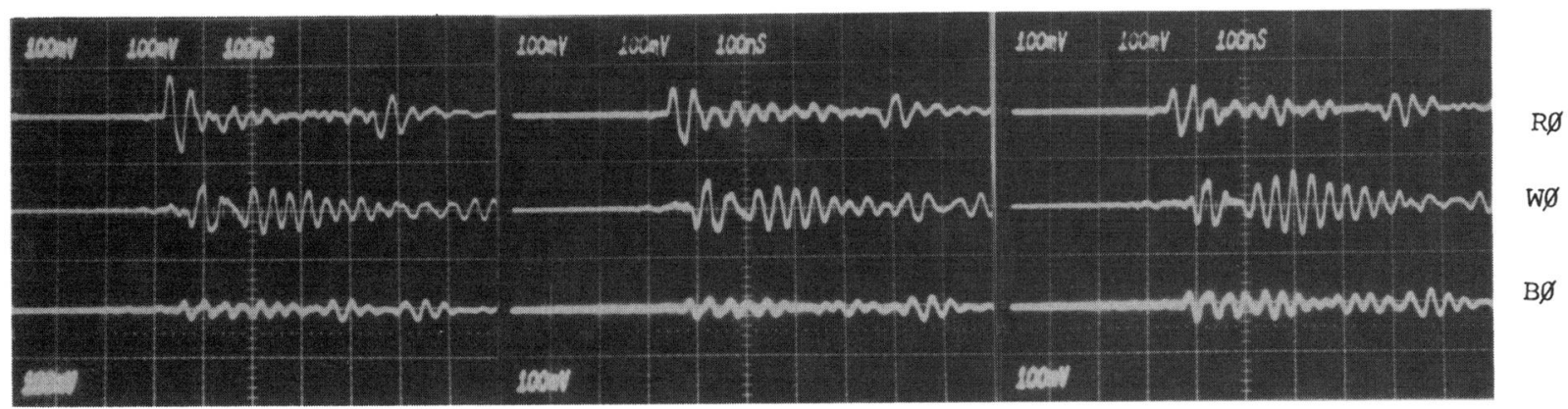

(a) inject at phase end

(b) inject 1 coil down from phase end

(c) inject 3 coils down from phase end

Figure 3: Response of capacitive couplers on Red, White and Blue phases of Machine $B$ to simulated PD pulses injected at different points in Red phase. The input voltage is a 100-V, 400-ns wide, 1-ns rise/fall pulse. The important response is the first peak of each waveform; electronic circuitry can ignore the subsequent ringing[4]. As the injection point moves electrically farther away from the terminal, the output response decreases. 
For both the simulation of noise and $\mathrm{PD}$, two voltage sources were used. One source was an AVTECH electronic pulse generator $(\mathrm{AV}-9)$ which produced a $100-$ $\mathrm{V}, 0.4-\mathrm{us}$ pulse with a 1-ns rise and fall time. The second pulse source approximated a PD or spark generator using an ignition coil driven by a special electronic circuit, fed to a spark gap. The "low" side of the spark gap was connected to the injection electrode, rotor, etc. The "spark" generator produced an initial 50-ns risetime, 2-kV pulse (Figure 1). The electrical arrangement for the tests is shown in Figure 2. In some cases the HP8568A spectrum analyzer in combination with a sweepfrequency oscillator measured the response from the $C T$.

\section{Machines Tested}

The response of the capacitive couplers and RF CT to simulated noise and PD was measured on three different machines. In two cases, data were also collected on two of the stators with the rotor removed. Table 1 summarizes the characteristics of the generators. Each machine had two parallel grounds per phase and each parallel consisted of seven- or twelve- (two groups of six) series connected coils (Roebel bar pairs). Machine $A$ is located at Ontario Hydro's Pickering Nuclear Generating Station while Machines $B$ and $C$ are at Nanticoke Thermal (coal) Generating Station.

TABLE 1

Machine Characteristics

\begin{tabular}{|c|l|c|c|c|c|}
\hline Machine & Rating & $\begin{array}{c}\text { Stator } \\
\text { Insulation } \\
\text { System }\end{array}$ & $\begin{array}{c}\text { Coils per } \\
\text { Parallel }\end{array}$ & $\begin{array}{c}\text { Tested with } \\
\text { Rotor } \\
\text { In }\end{array}$ & $\begin{array}{c}\text { Rotor } \\
\text { Out }\end{array}$ \\
\hline A & $\begin{array}{l}540 \mathrm{MW} \\
25 \mathrm{kV} \\
1800 \mathrm{rpm}\end{array}$ & epoxy/mica & 12 & Yes & Yes \\
B & $\begin{array}{l}540 \mathrm{MW} \\
25 \mathrm{kV} \\
3600 \mathrm{rpm}\end{array}$ & mica folium & 7 & Yes & Yes \\
$\mathrm{C}$ & $\begin{array}{l}540 \mathrm{MW} \\
25 \mathrm{kV} \\
3600 \mathrm{rpm}\end{array}$ & epoxy/mica & 7 & Yes & No \\
\hline
\end{tabular}

\section{RESULTS}

\section{Capacitive Coupler Detection}

\section{Response to Simulated Partial Discharge}

Photographs of the typical response to simulated $P D$ injected at three points in the Red phase of Machine $B$ are shown in Figure 3. The three oscilloscope traces in each photograph show the detected signals from the Red, White and Blue phase capacitive couplers respectively. No matter how far into the winding the Red phase signal is injected, the initial peak of the detected signal is highest in Red phase. Similarly, pulses injected into White and Blue phase parallels yielded the highest pulses at the White and Blue phase capacitive couplers, respectively. When injecting a pulse into one phase, the signals detected on the other phases may eventually achieve a significant magnitude some time after the first peak (Figure 3 ).

The shapes of the signals shown in Figure 3 are similar for all the windings tested. The risetime of the responses to simulated $P D$ were $15 \mathrm{~ns}$ or less, and the ringing frequencies are about $25 \mathrm{MHz}$. The pulse shape

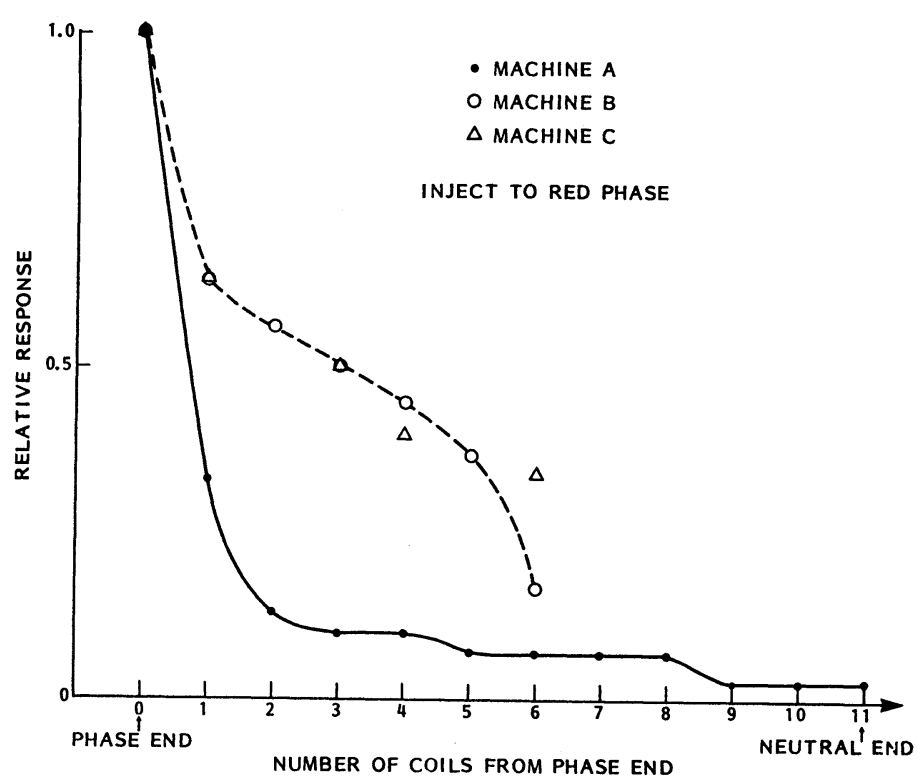

Figure 4: Relative response at the capacitive couplers of three different generators from simulated $P D$ injected at various points in a winding parallel. The phase end response is equal to 1.0 . In all cases, the rotor is in the machine.

was the same whether the electronic or the spark gap voltage source was used. For Machines $A$ and $B$, measurements were also taken with the rotor removed, and the isolated phase bus disconnected. In these cases, the risetime of the initial peak was slightly shorter, the magnitude was about 5 times larger and the signal ringing frequency was about $50 \mathrm{MHz}$. It was not possible to determine if these changes were due to the rotor, the IPB, or both.

As the injection point of the simulated PD is moved from the phase end of a parallel down $1,2,3$, etc coils, the first peak of the signal at the phase-end decreases (Figure 4). The attenuation of the signal as it propagates to the phase-end coupler is significantly greater for the four-pole winding in Machine A than for the other machines. Detection of PD from coils which are more than a few coils down from the phase end will be difficult in generators with windings similar to Machine A. The relative attenuation characteristic shown in Figure 4 was not affected when the rotors were removed and the IPB disconnected.

The loss of sensitivity to PD deep in the winding caused by pulse attenuation may not be too serious because: (1) any general deterioration of the insulation system due to aging or shrinkage leading to PD will occur in the line-end coils at least as fast as in any other, and (2) the most intense PD will be at the highest voltage in
any case, ie, in the line-end coil.

Response to Simulated Noise:

Figure 5 shows the responses at the phase-end capacitive couplers from voltage pulses injected into the rotor field winding of Machine $B$ at one of the slip rings. The first peak of the response to "slip ring noise" is about the same on all three phases. Another difference when comparisons to the simulated PD in Figure 3 are made, is that the response has a slightly longer risetime, and a more complicated ringing pattern. Also, the output has enough low-frequency response to follow the 


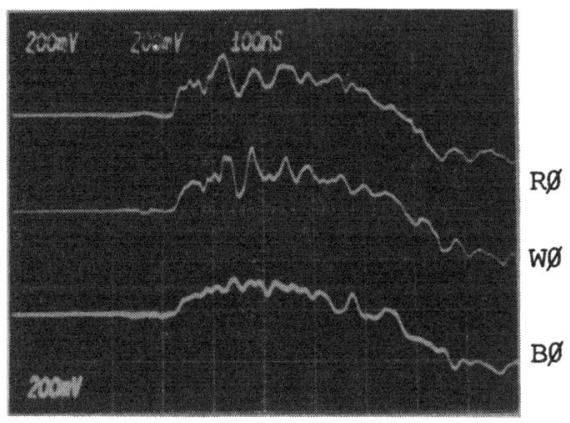

Figure 5: Response of the capacitive couplers in Machine $B$ to simulated noise (a 100-V, 400-ns wide pulse) injected into the rotor slip ring. The initial response from all three phases is similar.

400 -ns wide input pulse. When a narrower pulse, or the spark-gap source is employed, the ringing immediately oscillates about zero (similar to Figure 6). For a 100-V input pulse, the slip-ring signal results in an output at the coupler about $50 \%$ greater than for simulated PD injected at the phase end. Injecting voltage pulses directly onto the rotor shaft produced the same response.

The capacitive coupler response to a signal injected to the stator frame (essentially a dead short to the voltage source) is shown in Figure 6. Again, the first peaks from all three phases have the same polarity and similar magnitudes. In most other respects also, the response resembles that from the rotor noise. The responses shown in Figures 5 and 6 from Machine B were typical of those found in the other generators.

\section{RF Current Transformer Detection}

For each of the PD and noise injection situations described above, the response of the RF CT was also measured. Figure 7 shows the response of the $C T$ to simulated PD injected at three points on the Red phase of Machine B. The output voltage into $50 \mathrm{ohms}$ is relatively small (about $5 \mathrm{mV}$ ) and oscillates at about $30 \mathrm{MHz}$ (the upper cutoff frequency of the CT). The magnitude of the initial peaks are independent of the $P D$ injection point. Thus the RF CT appears capable of detecting PD throughout the entire winding.

The response of the CT to simulated noise was quite different. Very large responses, more than 100 times greater than for simulated PD with the same injected voltages, were measured (Figure 8). The outputs recorded mimic the $400-\mathrm{ns}$ wide, $100-\mathrm{V}$ pulses injected

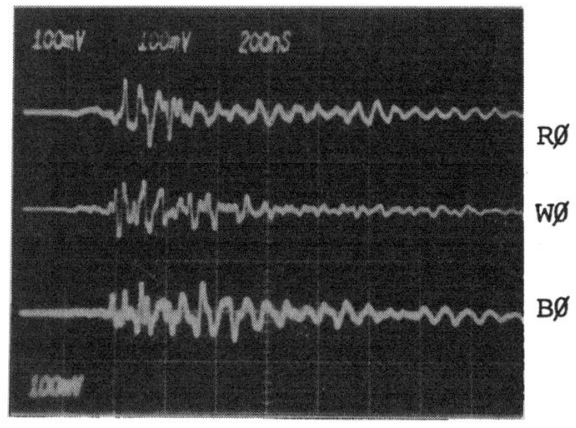

Figure 6: Response of capacitive couplers in Machine $B$ to simulated groundrise noise. A 100-V, 400-ns wide pulse was injected into the stator frame, exciter end, about $6 \mathrm{~m}$ from the stator frame ground reference point.

into the slip ring and the stator frame, except for the longer output risetime. The RF CT clearly responds preferentially to noise.
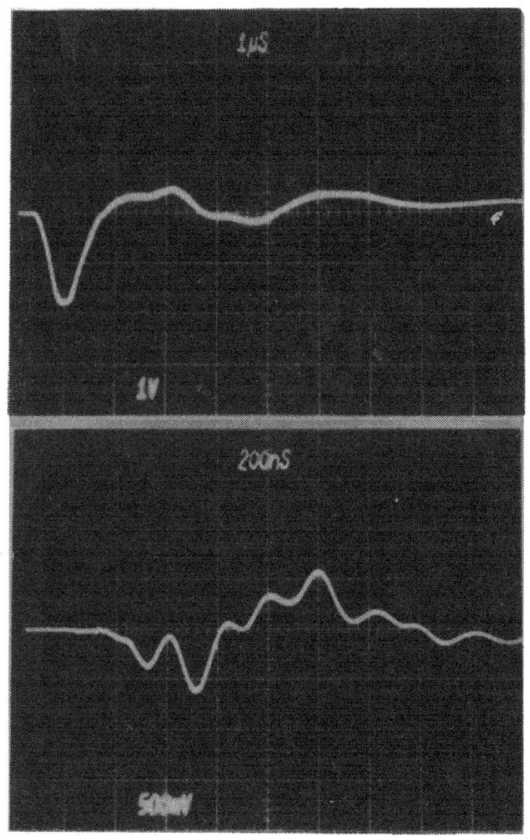

(b)

Figure 8: RF CT output on Machine B to simulated noise on the (a) slip ring and (b) stator frame (similar to Figures 5 and 6 ). Note the very high magnitude output compared to Figure 7.

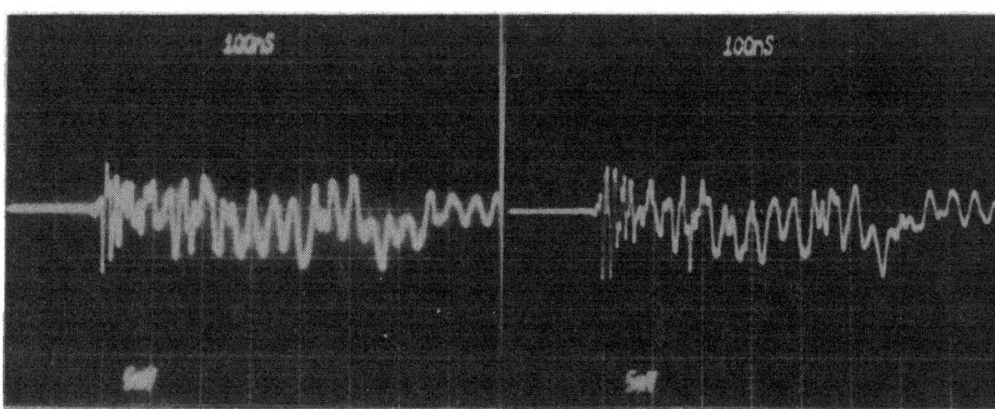

(a) inject at phase end (b) inject 1 coil down from phase end

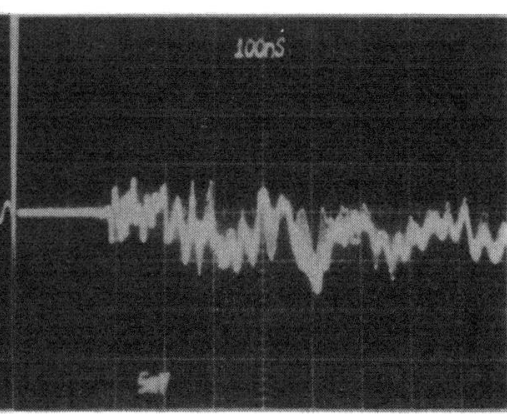

(c) inject 6 coils down from phase end (1 coil from neutral)

Figure 7:: Response of the RF current transformer on Machine $B$ to simulated PD injected at several points in the winding (as in Figure 3). The output response is relatively independent of the location of the PD. 
Since the RF CT detection method is often used in the frequency domain model[3], the frequency response characteristics of the winding were investigated. Figure 9 shows the output of the CT when a sweep-frequency oscillator (HP675A) is directly connected to the Red phase terminal of Machine $B$, at the IPB. There are several frequencies which propagate with relatively little attenuation. The response from the other phases is similar.

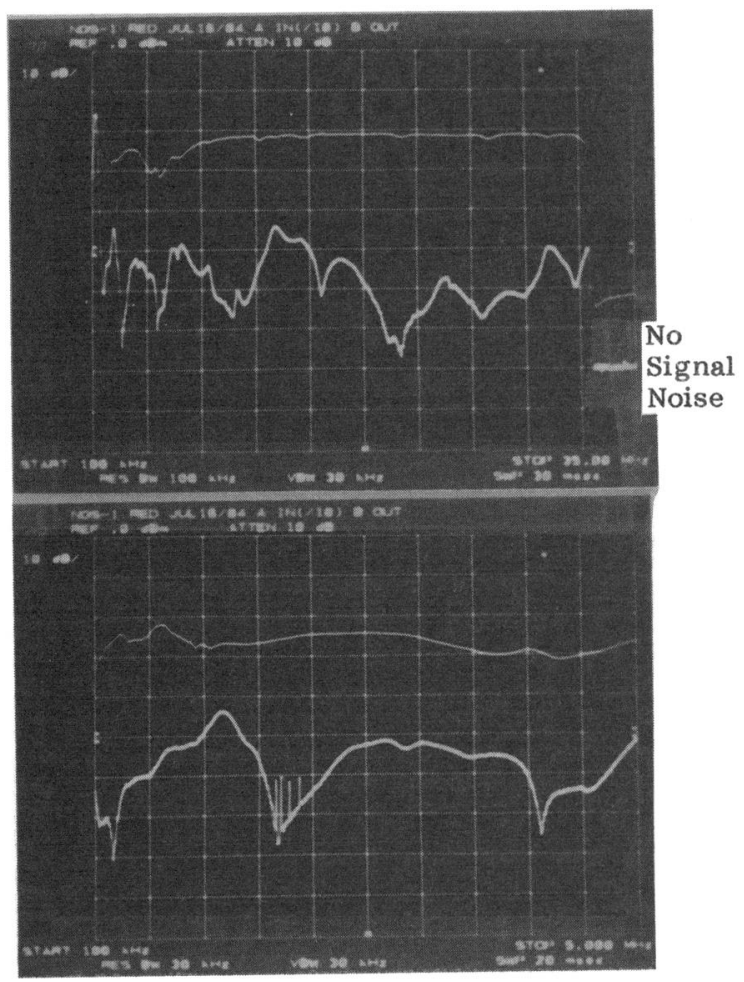

Figure 9: Frequency response spectra of the $R F C T$ in Machine $B$ when injecting a sinusoidal voltage to the terminal of Red phase. The scan extends linearly from 100 $\mathrm{kHz}$ to $35 \mathrm{MHz}$ (top photograph). The lower photograph shows an expansion from $100 \mathrm{kHz}$ to $5 \mathrm{MHz}$. For each photograph, the upper trace is the input signal magnitude from the sweep oscillator, and the lower trace is the CT output. The vertical scale is relative magnitude, $10 \mathrm{db} /$ division.
It was possible to make contact to the copper at several locations in a parallel in a winding similar to Machine A. The output of the sweep-frequency oscillator was injected into the winding at these points and the output of the CT was recorded on the spectrum analyzer. The spectra shown in Figure 10 indicate that the frequency response does change depending on the location of the electrical signal in the winding, especially at frequencies less than about $6 \mathrm{MHz}$.

\section{CONCLUSIONS}

Pulse propagation tests simulating partial discharge and electrical noise on three standstill turbine generators indicate that there are significant differences between PD and noise pulses as detected by capacitive couplers at the phase terminals or by an RF current transformer at the neutral terminal. For the capacitive couplers, the pulse response is greatest in the phase which has the PD; whereas for noise, the initial signal magnitude is much the same on all three phases. The PD signal is significantly attenuated in some windings. For the RF CT, the output signal in response to PD is very low, although the response is not sensitive to the location of the simulated PD in the winding. A very strong output, including good low-frequency response, is obtained from simulated noise. Utilization of the different responses of the detectors to noise and partial discharge may provide a base for a useful algorithm to monitor partial discharge in the HV-insulation systems of turbine generators during normal service.

\section{ACKNOWLEDGEMENTS}

This work has been supported in part by the R\&D Division of the Canadian Electrical Association, and by the Technical University of Denmark, The Danish Technical Research Council, NATO Scientific Affairs Division and The Research Association of the Danish Electricity Supply Undertakings (DEFU).

\section{REFERENCES}

1. D.M. Ryder, J.W. Wood, P.L. Gallagher, "The Detection and Identification of Overheated Insulation in Turbogenerators", IEEE Trans PAS-98, Jan 1979 , p333.

2. J.S. Johnson, M. Warren, "Detection of Slot Discharge in High Voltage Stator Windings During Operation", AIEE Trans, Vol 70, Part II, 1951, p1933.

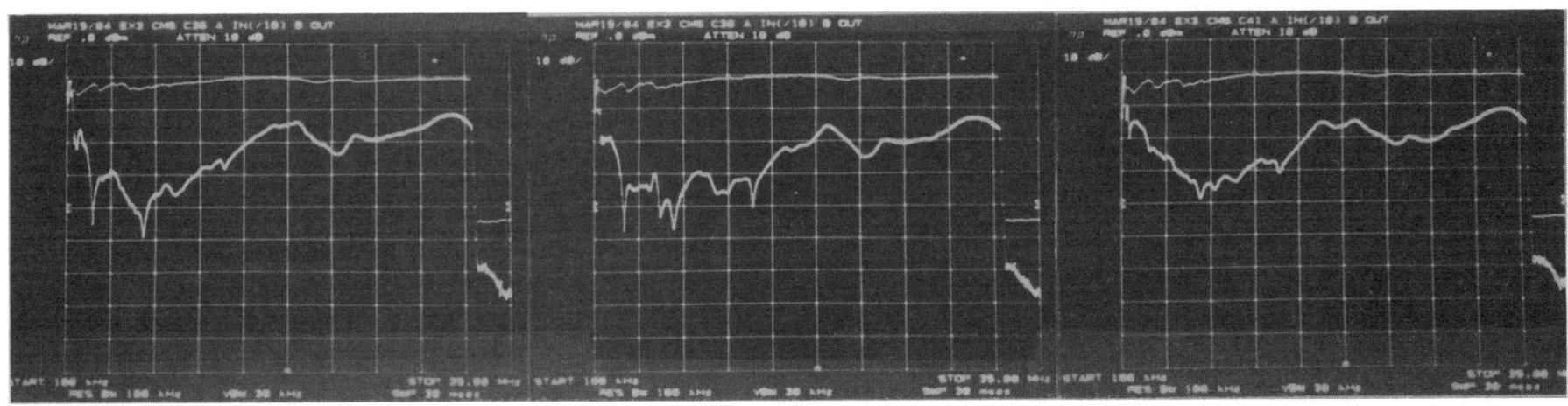

(a) inject at phase end

(b) inject 2 coils from phase end (c) inject 5 coils from phase end

Figure 10: Response of RF CT to a sweep-frequency oscillator voltage injected directly onto the copper conductor at several points in a winding parallel in Red phase of Machine A. In all cases the frequency (horizontal scale) is swept from $100 \mathrm{kHz}$ to $35 \mathrm{MHz}$. The upper trace is the input and the lower trace is the output. 
3. F.T. Emery, R.T. Harrold, "On-Line Incipient Arc Detection in Large Turbine Generator Stator Windings", IEEE Trans PAS-99, Nov 1980, p2232.

4. M. Kurtz, J.F. Lyles, G.C. Stone, "Application of Partial Discharge Testing to Hydro Generator Maintenance", IEEE Trans PAS-103, Aug 1984, p2148.

5. M. Kurtz, et. al., "Diagnostic Testing of Generator Insulation Without Service Interruption", CIGRE Paper 11-09, Aug 1980.

\section{Discussion}

J. E. Timperley (American Electric Power Service Corporation, Columbus, $\mathrm{OH}$ ): The authors have proposed an interesting method to inject test signals into a machine stator winding without direct conductor contact. I have two questions pertaining to the use of PD injection.

1) Have your tests included application to motors or hydroelectric generators where coils with two or more turns are present?

2) The response of the white phase to an impulse, Fig. 3 (C), appears to be a ringing frequency of about $26 \mathrm{MHZ}$. This also appears to correspond to a minimum current, or maximum impedence point in Fig. 9. Have the authors investigated this or other resonance points and its relationship with winding inductance and capacitance? We have had some success in using standing wave equations to determine several possible resonant frequencies, 26 MHZ, for example, would indicate a slot length of about 5 meters. This length seems short for a $540 \mathrm{MW}, 3600 \mathrm{rpm}$ unit.

\section{REFERENCE}

J. E. Timperley, "Detection of Insulation Deterioration Through Electrical Spectrum Analysis," Proceedings of the 16th Electrical/Electronics Insulation Conference, October 3 - 6, 1983, p. 60 - 64, IEEE Publication No. CH1952-1/83 0000-0060.

Manuscript received February 25, 1985

M. Henriksen, G. C. Stone and M. Kurtz: We thank Mr. Timperley for his interest in this paper.

In reply to his questions:

1. We have studied pulse propagation responses and attentuation through the winding in a large number of multiturn motors and hydro generators, with however some minor differences in detail. In most cases for motors (slated for repair or rewind) we have been able to gain access to bare copper in the end winding. On hydro generators we have frequently used metal foil wrapped on a pole jumper to act as a coupling capacitor for pulse injection(1).

2. As Mr. Timperley notes, there does appear to be a correspondence between the ringing frequency and the resonance point in Fig. 9. To date we have not investigated the internal resonances as a function of winding parameters in the partial discharge studies for diagnostic purposes. However, some work in this direction is underway in another project connected with turn insulation capability. The slot length in these machines is about $5.5 \mathrm{~m}$.

\section{REFERENCE}

[1] M. Kurtz, G. C. Stone, "Diagnostic Testing of Generator Insulation, Part II, An Improved Partial Discharge Test," CEA Research Report, Contact RP76-17, Sept. 1978.

Manuscript received March 29, 1985 